\title{
Clinical penetrance in hereditary hemochromatosis: estimates of the cumulative incidence of severe liver disease among HFE C282Y homozygotes
}

\author{
Scott D. Grosse, PhD ${ }^{1}$, Lyle C. Gurrin, BSc (Hons), PhD ${ }^{2,3}$, Nadine A. Bertalli, BHSc (Hons) ${ }^{2,3}$ and \\ Katrina J. Allen, $\mathrm{MD}, \mathrm{PhD}^{2,4,5}$
}

Iron overload (hemochromatosis) can cause serious, symptomatic disease that is preventable if detected early and managed appropriately. The leading cause of hemochromatosis in populations of predominantly European ancestry is homozygosity of the C282Y variant in the HFE gene. Screening of adults for iron overload or associated genotypes is controversial, largely because of a belief that severe phenotypes are uncommon, although cascade testing of first-degree relatives of patients is widely endorsed. We contend that severe liver disease (cirrhosis or hepatocellular cancer) is not at all uncommon among older males with hereditary hemochromatosis. Our review of the published data from a variety of empirical sources indicates that roughly 1 in 10 male HFE C282Y homozygotes is likely to develop severe liver disease during his lifetime unless iron overload is detected early and treated. New evidence from a randomized controlled trial of treatment allows for evidence-based management of presymptomatic patients. Although population screening for HFE C282Y homozygosity faces multiple barriers, a potentially effective strategy for increasing the early detection and prevention of clinical iron overload and severe disease is to include HFE C282Y homozygosity in lists of medically actionable gene variants when reporting the results of genome or exome sequencing.

Genet Med advance online publication 3 August 2017

Key Words: genetic epidemiology; genomics; hereditary hemochromatosis; iron overload; penetrance

\section{INTRODUCTION}

Hereditary hemochromatosis $(\mathrm{HH})$ attributable to mutations on the HFE gene is the most common autosomal recessive disorder among adults of northern European origin. ${ }^{1}$ It occurs in 1 in 300 non-Hispanic whites in the United States ${ }^{2}$ and up to 1 in 150 people of northwestern European ancestry. ${ }^{3,4}$ Approximately $80-90 \%$ of $\mathrm{HH}$ cases of phenotypic disease are due to homozygosity for the C282Y allele in the HFE gene. ${ }^{5}$ Homozygotes, especially males, typically develop iron overload with advancing age. In a prospective Australian cohort study drawn from the general population, serious iron overload, with serum ferritin (SF) $\geq 1,000 \mu \mathrm{g} / \mathrm{l}$, was found to occur among $35 \%$ of male homozygotes and $6 \%$ of females at a median age of 65 years. ${ }^{4}$

Iron overload can result in life-threatening clinical complications, most notably severe liver disease such as cirrhosis or hepatocellular carcinoma (HCC), ${ }^{4,6-9}$ and HCC is an often lethal complication of cirrhosis. ${ }^{10,11}$ These complications are readily preventable in presymptomatic patients through minimally invasive interventions. Specifically, clinical guidelines recommend that individuals with $\mathrm{HH}$ with $\mathrm{SF}$ above the reference range undergo periodic phlebotomy until a target SF concentration is reached. ${ }^{12,13}$ Patients are recommended to undergo annual SF monitoring; an invasive liver biopsy is no longer required. With appropriate management, patients can generally avoid the development of clinical disease. ${ }^{14,15}$ In particular, asymptomatic HFE C282Y homozygotes whose SF concentrations remain below $1,000 \mu \mathrm{g} / \mathrm{l}$ rarely develop cirrhosis. ${ }^{15-18}$ Although $\mathrm{HH}$ patients with preexisting liver disease should be treated, ${ }^{12}$ there is a low degree of reversibility of liver cirrhosis and other organ damage; therefore, presymptomatic detection of $\mathrm{HH}$ is critical. ${ }^{13,19-22}$

An unanswered question about the management of HFE C282Y homozygotes is the optimal target concentration of SF. Clinical guidelines recommend iron depletion, with a target concentration of $50-100 \mu \mathrm{g} / \mathrm{l}^{12-14}$ However, there is limited evidence on whether patients with only moderately elevated SF $(300-1,000 \mu \mathrm{g} / \mathrm{l})$ benefit from phlebotomy and whether the optimal target should be $<300 \mu \mathrm{g} / \mathrm{l}$ (the upper limit of the clinically normal range) or $<100 \mu \mathrm{g} / \mathrm{l}$. The results of a randomized controlled trial comparing iron reduction by erythrocytapheresis with sham treatment by plasmapheresis, ${ }^{23}$ which will be available later this year, will for the first time provide high-quality evidence to answer this question.

Despite the lack of definitive, randomized trial evidence of treatment efficacy, population screening of asymptomatic

\footnotetext{
${ }^{1}$ National Center on Birth Defects and Developmental Disabilities, Centers for Disease Control and Prevention, Atlanta, Georgia, USA; ${ }^{2}$ Department of Gut and Liver, Murdoch Childrens Research Institute, Melbourne, Victoria, Australia; ${ }^{3}$ Centre for Molecular, Environmental, Genetic and Analytic Epidemiology, University of Melbourne, Melbourne, Victoria, Australia; ${ }^{4}$ Department of Paediatrics, University of Melbourne, Melbourne, Victoria, Australia; ${ }^{5}$ Department of Gastroenterology, Royal Children's Hospital, Melbourne, Victoria, Australia. Correspondence: Scott D. Grosse (sgrosse@cdc.gov)
} 
adults to detect the signs of $\mathrm{HH}$ to allow for preventative measures has been proposed by some clinical experts. ${ }^{24,25}$ By contrast, experts in population screening have not been supportive of screening for $\mathrm{HH}$, largely because severe clinical disease is widely believed to be relatively uncommon among people with HFE genotypes associated with $\mathrm{HH}$ despite the high frequency of these alleles. ${ }^{1,5,26-29}$ In particular, in 2006, the US Preventive Services Task Force (USPSTF) recommended against routine genetic screening of the general adult population for HFE mutations because "clinically important disease due to $\mathrm{HH}$ appears to be rare." 30 Several other US groups have concurred with the USPSTF stance on universal testing, but have endorsed genetic counseling and testing for first-degree relatives of patients with HFE hemochromatosis. ${ }^{31}$

Skeptics of the clinical utility of genetic testing have cited the allegedly low clinical penetrance of HFE genotypes: "Variants in the HFE gene were once considered so informative they could be used to screen the general population; when the gene was studied in large populations, the chance that carriers expressed hemochromatosis was revised from more than $80 \%$ to less than $1 \% . " 32$

In fact, because $\mathrm{HH}$ is an autosomal recessive disorder, carriers of HFE variants do not express hemochromatosis. ${ }^{33}$ The $80 \%$ figure refers to the cumulative, lifetime incidence of iron overload among a large, representative sample of male homozygotes. ${ }^{4}$ By contrast, the $<1 \%$ estimate refers to the presence of the combination of liver disease, diabetes, heart failure, and bronze skin among 1 of 152 homozygotes identified in a screening study, ${ }^{34}$ and is not a downward revision of the estimated risk of iron overload. In the same screening study, the prevalence of medical diagnoses of liver problems was $8.1 \%$ among 124 homozygotes of both sexes versus $4.1 \%$ of wild-type controls-a statistically significant difference. ${ }^{34}$

Others have used the cross-sectional prevalence of liver disease as a proxy measure of clinical penetrance in $\mathrm{HH}$. For example, the USPSTF ${ }^{30}$ cited Whitlock et al. as noting that just $1.4 \%$ of 72 newly diagnosed HFE C282Y homozygotes of both sexes pooled from seven studies were confirmed by biopsy to have liver cirrhosis, although the authors of that evidence review acknowledged that cross-sectional data cannot be used to estimate penetrance. ${ }^{35}$ Similarly, a modeling study by Rogowski ${ }^{36}$ calculated the pooled cross-sectional prevalence of biopsy-determined liver cirrhosis among male homozygotes in seven $\mathrm{HH}$ screening studies. ${ }^{4,37-42}$ The pooled estimate was $3.5 \%$, with lower- and upper-bound estimates of 1.6 and $5.6 \%$, respectively. ${ }^{36}$ In modeling the cost-effectiveness of $\mathrm{HH}$ screening strategies, Rogowski used the pooled cross-sectional prevalence estimate of liver cirrhosis among male homozygotes of all ages as the estimate of their lifetime risk of developing severe liver disease. ${ }^{36}$

The use of the cross-sectional prevalence of clinical disease as a proxy for penetrance can be misleading. The standard epidemiologic measure of clinical penetrance or disease expression is the cumulative risk or incidence of disease to a given age, typically 70 years, whether absolute or relative to the background risk in the population. ${ }^{43}$ For example, the penetrance of Lynch syndrome has been assessed as the cumulative incidence, to the age of 70 , of Lynch syndromeassociated cancers. ${ }^{44}$ Analogous to cancer in Lynch syndrome, the risk of severe liver disease in individuals with $\mathrm{HH}$ increases with age. In particular, liver cirrhosis is rare among homozygotes before the age of $40 .{ }^{45}$ Therefore, the lifetime cumulative incidence of liver disease among older adults is inevitably higher than the cross-sectional prevalence among adults of all ages. Although Whitlock et al. ${ }^{43}$ concluded that the penetrance of clinical disease in $\mathrm{HH}$ was unknown, one can estimate the clinical penetrance of a genotype, such as HFE C282Y homozygosity, as the cumulative incidence of disease to age 70 using a life-table model and age-specific prevalence estimates. ${ }^{46}$

The purpose of this work was to review the epidemiologic evidence from population-based studies on the clinical penetrance of HFE C282Y homozygosity in males in terms of the cumulative risk of severe liver disease. We excluded studies of clinic-based samples of $\mathrm{HH}$ patients and familyhistory-based samples of relatives of $\mathrm{HH}$ patients. Ascertainment bias from such samples for other conditions has been shown to result in overestimates of penetrance. For example, older estimates of the cumulative incidence to age 70 of colorectal cancer among male carriers of MLH1/MSH2 mutations in the range $65-82 \%$ have been supplanted by unbiased estimates of $41-48 \%$ based on representative samples. ${ }^{44}$

\section{NATURAL HISTORY ESTIMATES OF THE PREVALENCE OF SEVERE LIVER DISEASES}

The focus of the present review was on two types of natural history study. One consisted of cohort studies in which representative groups of asymptomatic adults were prospectively monitored for the development of disease symptoms and, at a later age, were retrospectively genotyped. The other consisted of analyses of clinical disease registries that use cross-sectional population estimates of the prevalence of HFE genotypes in the denominators to calculate rates.

\section{Cohort studies}

The natural history of a disorder can be assessed through retrospective analyses of data collected prospectively on cohorts of untreated patients. In their systematic review of studies published through February 2005, Whitlock et al. ${ }^{35}$ identified two longitudinal studies reporting estimates of cases of disease in initially nondiseased C282Y homozygotes. ${ }^{39,40}$ Those two studies, along with two other cohort studies that were subsequently published, ${ }^{4,47}$ are summarized in Table $\mathbf{1 .}$

The Copenhagen City Heart study in Denmark enrolled subjects of all ages in 1976, and during 1999-2001, investigators genotyped 9,174 study participants who had been evaluated during 1991-1994. ${ }^{40,48}$ None of the six male HFE C282Y homozygotes still alive in 2001, at ages 35-85 years, was reported by Andersen et al. to have symptomatic liver disease or other overt clinical manifestations of 
Table 1 Retrospective analyses of cohort studies of untreated C282Y HFE homozygotes with information on liver disease end points

\begin{tabular}{|c|c|c|c|c|}
\hline Study & Study location & $\begin{array}{l}\text { \# Untreated } \\
\text { homozygotes }\end{array}$ & $\begin{array}{l}\text { Length of } \\
\text { follow-up }\end{array}$ & $\begin{array}{l}\text { No. male homozygotes with liver disease } \\
\text { detected }\end{array}$ \\
\hline $\begin{array}{l}\text { Atherosclerosis Risk in } \\
\text { Communities(ARIC })^{47}\end{array}$ & United States & $22 \mathrm{M} ; 23 \mathrm{~F}$ & $15-17$ years & $\begin{array}{l}1 \text { fatal liver cancer; } 1 \text { hospital discharge } \\
\text { diagnosis of liver disease; } 1 \text { physician diagnosis } \\
\text { of cirrhosis }\end{array}$ \\
\hline Healthlron ${ }^{4}$ & & $\begin{array}{l}45 \mathrm{M} \text { who were aged } \\
\geq 60 \text { years at follow-up }\end{array}$ & & 2 with HCC; 2 with biopsy-confirmed cirrhosis \\
\hline
\end{tabular}

F, female; HCC, hepatocellular carcinoma; M, male.

hemochromatosis. Furthermore, liver disease was not reported as a cause of death for the one male homozygote who died between the evaluation period (1991-1994) and 2001. ${ }^{40}$ However, there was a large, unexplained deficit in male homozygotes, with the prevalence of homozygosity only half as high as among females. ${ }^{48}$ It is unknown whether severe liver disease might have occurred among male homozygotes who died prior to genotyping.

The Busselton study followed a population cohort in a town in Western Australia for many years without knowledge of iron status or genotype. Subsequently, in 1998, the investigators collected blood samples from a random sample of 3,011 unrelated subjects aged 20-79 years, most of whom had previously been followed since at least $1981 .{ }^{39}$ The investigators identified $16 \mathrm{HFE} \mathrm{C} 282 \mathrm{Y}$ homozygotes, including 12 newly diagnosed cases. Ten of the newly diagnosed homozygotes (6 women and 4 men) had stored serum specimens from 1981, 1994, and 1998, which were used to determine changes over time in SF values. Of four untreated male homozygotes who had been followed since 1981 and were aged 46 to 78 in 1998, one with SF $>1,000 \mu \mathrm{g} / \mathrm{l}$ had cirrhosis (age 52). ${ }^{39}$

The Atherosclerosis Risk in Communities study retrospectively assessed data, including HFE genotyping, on 14,485 US adults aged 45-64 years in 2004, who had been followed from the 1987-1989 study baseline. ${ }^{47}$ Of 10,800 non-Hispanic white subjects, 45 were HFE C282Y homozygotes (22 male). Two (9.1\%) male homozygotes had confirmed severe liver disease: one case each of fatal liver cancer and a physician's diagnosis of cirrhosis (J. Pankow, personal communication, and ref. 47).

The HealthIron study, conducted in Melbourne, Australia, collected data from 31,192 participants of northern European ancestry who had enrolled during 1990-1994 in a prospective 12-year Melbourne Collaborative Cohort study of the influence of diet and lifestyle factors on chronic disease. ${ }^{4}$ The HealthIron study collected data during 2004-2006 on 74 male and 84 female surviving $H F E$ C282Y homozygotes (median age: 65.2 years), among whom $28.4 \%$ of males and $1.2 \%$ of females had documented iron overload in addition to disease symptoms. Of 17 surviving male HFE C282Y homozygotes who underwent liver biopsy, 12 had either biopsy-confirmed liver fibrosis $(n=10)$ or cirrhosis $(n=2)$. Two other male C282Y homozygotes were diagnosed with HCC. ${ }^{4}$ All four male homozygotes who had either confirmed cirrhosis or HCC at follow-up were aged $\geq 60$, as were 45 of the 74 male homozygotes (unpublished age-stratified analysis by N.A.B.). Thus, although the cumulative incidence of severe liver disease among males at follow-up was $5.4 \%$, it was $8.9 \%$ among male homozygotes aged $\geq 60$ at follow-up.

We estimated the pooled prevalence of severe liver disease among older male homozygotes in the four cohort studies in Denmark, ${ }^{40}$ Australia, ${ }^{4,39}$ and the United States. ${ }^{47}$ On the basis of an unpublished tabulation, we restricted the Australian cohort to subjects who were followed to at least 60 years of age; we were unable to impose the same restriction on the other studies. The pooled prevalence of severe liver disease was $9.0 \%$ (7 of 78) (Table 1). The 95\% confidence interval for this point estimate of the proportion was rather wide at $2.6-15.3 \%$.

\section{Previous modeling estimates}

Before our study, one previous estimate of the cumulative incidence of severe liver disease among HFE C282Y male homozygotes had been published. ${ }^{49}$ The starting point for that estimate was cross-sectional data by age, derived from a Norwegian screening study.

The HUNT study invited the adult population in NordTrøndelag County, Norway, to participate in transferrin saturation screening, and $65 \%$ of men and $73 \%$ of women were screened. The investigators reported on 177 men newly diagnosed with $\mathrm{HH}$ through transferrin saturation screening. Most $(n=150)$ were confirmed by genotyping to be HFE C282Y homozygotes, and 107 of those underwent biopsies, which revealed three (3\%) cases of biopsy-confirmed cirrhosis. ${ }^{3}$

In a modeling analysis published in 2002, Asberg et al. ${ }^{50}$ pooled data regarding the 107 male homozygotes from the HUNT study with data from a clinic-based US screening study by Phatak et al. ${ }^{51}$ Phatak et al. conducted transferrin saturation and SF screening of 16,031 primary-care patients 
( $42 \%$ male) not previously diagnosed with $\mathrm{HH}$, among whom 70 were ultimately classified as either proven or probable $\mathrm{HH}$ cases, including 25 with biopsy-proven HH. No genotyping was performed that would be needed to identify homozygotes. Asberg et al. extracted information on 16 males aged 23 to 72 with biopsy-proven $\mathrm{HH}$, two of whom had biopsyproven liver cirrhosis: one aged 42 and one aged 63. Asberg et al. fit a polynomial curve of cirrhosis-free survival to the pooled data from the two studies by age, which was said to show similar patterns, even though the frequency of biopsy-confirmed cirrhosis was four times higher in the US study ( 2 of 16) than in the Norwegian study ( 3 of 107). They analyzed the pooled data to estimate annual rates of the incidence of cirrhosis by 5-year intervals from ages 30-35 to 60-65 among male homozygotes newly diagnosed with $\mathrm{HH}$ by screening.

Subsequently, in a 2007 publication, Asberg et al. combined the modeling estimates derived from the Norwegian and US screening studies with data regarding 5 cases of cirrhosis among 16 males in the HUNT cohort who had been previously diagnosed with $\mathrm{HH}^{49}$ The investigators estimated the cross-sectional prevalence of cirrhosis among men of all ages with $\mathrm{HH}$ as between $3.4 \%$, assuming that no one who was not screened had $\mathrm{HH}$-associated liver cirrhosis, and 5.0\%, assuming the same risk of cirrhosis among males who were not screened as those who were screened. The cumulative incidence was estimated as $0.2 \%$ at the age of $35,2.7 \%$ at age $45,6.4 \%$ at age 55 , and $11.0 \%$ at age $65 .{ }^{49}$ As already noted, the investigators did not have actual data regarding homozygotes in the US screening study, and combining those data probably resulted in an overestimation of the incidence of cirrhosis.

\section{DISCUSSION}

It is standard practice to use lifetime incidence to estimate clinical penetrance and the preventable burden of disease. For example, testing for Lynch syndrome in tumor samples of newly diagnosed patients with colorectal cancer has been endorsed as a population health strategy based on estimates of the cumulative incidence of colorectal cancer of $35-45 \%$ and a roughly $60 \%$ lower risk of cancer among carriers who follow regular colonoscopic surveillance. ${ }^{52-55}$ Likewise, crosssectional prevalence estimates are not sufficient for estimating clinical penetrance in $\mathrm{HH}$, and estimates of lifetime incidence must be considered.

The lifetime incidence of severe liver disease alone appears to be approximately $9 \%$ (95\% confidence interval: $2.6-15.3 \%$ ) of male HFE C282Y homozygotes of European ancestry based on data from prospective cohort studies. This is a lowerbound point estimate; because of the lack of systematic liver biopsies, studies potentially underascertain the frequency of occurrence of severe liver disease. Furthermore, not all subjects in those studies were followed to at least 60 years of age, let alone age 70. A longer follow-up would be needed to accurately establish the lifetime cumulative incidence. The $9 \%$ point estimate is similar to the projected incidence of severe liver disease to age 65 estimated in a modeling analysis of pooled Norwegian and US crosssectional data derived from screening studies; however, the US data in the aforementioned study was restricted to biopsyconfirmed $\mathrm{HH}$ cases and probably excluded many HFE C282Y homozygotes.

Although the cumulative incidence of either liver cirrhosis or cancer to age 60 among male HFE C282Y homozygotes cannot be precisely estimated, these outcomes are not "rare". Furthermore, severe liver disease is just the tip of the iceberg in $\mathrm{HH}$ disease expression. The overall clinical penetrance in terms of iron overload-related clinical symptoms, including liver fibrosis, among male homozygotes has been estimated as $28 \%, 4,56$ which is roughly three times higher than that of severe liver disease alone.

The implication of the finding that almost 1 in 10 male C282Y homozygotes is likely to develop severe liver disease in the absence of presymptomatic detection is that widespread detection could avert considerable numbers of premature deaths in populations of predominantly European ancestry. Rogowski ${ }^{36}$ concluded that population screening of 30-yearold German males would reduce preventable deaths but would not be cost-effective relative to a commonly used threshold value. Given that the number of cases of severe liver disease among older male homozygotes appears to be 2.5-3 times higher than was assumed in that study, a case could be made that population screening for $\mathrm{HH}$ should be reconsidered.

A newly published cost-effectiveness model of population screening strategies for $\mathrm{HH}$ on which L.C.G. collaborated has supported the argument that routine genotyping at age 30 in Australian males of northern European ancestry would be highly cost-effective. ${ }^{57}$ The authors calculated that routine genetic screening of such males at age 30 and females at age 45 could identify $40 \%$ of all homozygotes in Australia, compared with the detection of roughly $3 \%$ of homozygotes using current testing strategies. The economic analysis was built on a state-transition model in which probabilities were informed by epidemiologic data from the HealthIron study. ${ }^{58}$ The study projected the impacts of screening on both length of life and health-related quality of life. ${ }^{57}$

However, an evidence-based case for population screening for $\mathrm{HH}$ still needs to be established. In particular, $\mathrm{HH}$ homozygotes are not underrepresented among the elderly, and hence they do not have a shorter life expectancy. ${ }^{59}$ Similarly, all-cause mortality is no higher for C282Y homozygotes, who on average have significantly reduced low-density lipoprotein cholesterol levels. ${ }^{47,60}$ Therefore, it is unclear whether the identification and management of homozygotes will extend life overall. In addition, many other challenges to population screening for $\mathrm{HH}$ remain, including the logistical and ethical issues involved with ethnicitytargeted offers of testing. ${ }^{1,61}$ By contrast, there is a lower evidentiary threshold for clinically recommended cascade testing of first-degree relatives, ${ }^{12,31}$ which is likely to be costeffective even if relatively few cases are detected. ${ }^{1,36}$ 
Another approach, besides cascade screening, to achieving more preclinical detection of adult HFE homozygotes is the incorporation of the HFE $\mathrm{C} 282 \mathrm{Y}$ variant in lists of medically actionable gene variants. This is because the threshold of benefit required to justify the return of a known variant when a patient undergoes gene sequencing is lower than for population screening. ${ }^{62,63}$ For example, it has been proposed that moderate clinical penetrance of roughly $40 \%$ might warrant population screening, but that for clinical reporting, a relative risk of $\geq 2$ for serious health outcomes would be sufficient. ${ }^{64}$ The authors noted odds ratios of 4-11 for liver disease associated with HFE C282Y homozygosity, ${ }^{64}$ but those findings were derived from a meta-analysis of case-control studies of samples of cases detected symptomatically (i.e., they were subject to ascertainment bias). 8

The Clinical Sequencing Exploratory Research Consortium was established at six US centers to evaluate the clinical return of findings from genomic sequencing. Based on evidence of potentially severe and completely preventable long-term complications in HFE C282Y homozygotes, all four of the consortium's sites working with adult populations classified this variant as medically actionable. ${ }^{63}$ In particular, the University of North Carolina NCGENES project has classified HFE among 17 genes associated with some of the most clinically actionable monogenetic disorders. ${ }^{65}$ Specifically, the HFE C282Y variant is reported; the other HFE variants associated with hemochromatosis-H63D/H63D and C282Y/ H63D-are not reported because of uncertain clinical implications.

In 2013, the American College of Medical Genetics and Genomics (ACMG) established a list of 53 genes for which "incidental" findings of gene sequencing could be recommended to be reported to patients. ${ }^{66}$ In 2016, the renamed ACMG Secondary Findings list was expanded to include 59 genes considered to be medically actionable. ${ }^{67}$ However, the process for deciding which gene variants should be classified as actionable has been disputed. ${ }^{64,68} \mathrm{~A}$ systematic framework was recently proposed to evaluate clinical actionability on the basis of four scored criteria (severity, likelihood of disease, effectiveness of interventions, and how risky, medically burdensome, or intensive an intervention would be) and the knowledge base. ${ }^{69}$ The authors assessed the 59 variants in version 2.0 of the ACMG Secondary Findings and found that 20 of the variants had a score of 9 or less on a 12-point scale. ${ }^{69}$ Applying those criteria to HFE C282Y would yield a score of 10 (a reasonable possibility of death or major morbidity, a $5-39 \%$ chance of a serious outcome, and highly effective and low-risk intervention). This score would appear to warrant its inclusion in the ACMG Secondary Findings list-more so than some variants currently included.

In conclusion, we believe that a conservative measure of the clinical penetrance of HFE-associated $\mathrm{HH}$ is the lifetime cumulative penetrance of severe liver disease, defined as cirrhosis or HCC. The perception that severe phenotypes attributable to $\mathrm{HH}$ are uncommon is due to the inappropriate use of the cross-sectional prevalence of disease as a proxy measure for a properly defined criterion for clinical penetrance. Our review of the findings from both crosssectional and cohort studies of $\mathrm{HH}$ indicates that the clinical penetrance of HFE C282Y homozygosity appears to be at least $8 \%$, which is substantially greater than estimates previously quoted in the literature. This has potential implications for population screening strategies, since using a higher clinical penetrance in cost-effectiveness models of testing for $\mathrm{HH}$ would be expected to result in more favorable estimates of the cost-effectiveness of testing for $\mathrm{HH}$ than those that have been previously published. This result also strengthens the case for the inclusion of HFE C282Y homozygosity in lists of medically actionable gene variants from genome or exome sequencing. Additional research on the long-term health outcomes of cohorts of individuals genotyped for HFE variants could yield more precise estimates of clinical penetrance, which could further inform decisions on ways to lessen the population health impact of hereditary hemochromatosis.

\section{ACKNOWLEDGMENTS}

The authors appreciate helpful comments on previous versions of this paper by Chris Bean, Dave Dotson, Mary Hulihan, Katie Kolor, Amanda B. Payne, and Wolf Rogowski. The findings and conclusions in this report are those of the authors and do not necessarily represent the official position of the Centers for Disease Control and Prevention.

\section{DISCLOSURE}

The authors declare no conflict of interest.

\section{REFERENCES}

1. Grosse SD, Rogowski WH, Ross LF, Cornel MC, Dondorp WJ, Khoury MJ Population screening for genetic disorders in the 21st century: evidence, economics, and ethics. Public Health Genomics 2010;13:106-115.

2. Steinberg KK, Cogswell ME, Chang JC, et al. Prevalence of C282Y and H63D mutations in the hemochromatosis (HFE) gene in the United States. JAMA 2001;285:2216-2222.

3. Asberg A, Hveem K, Thorstensen K, et al. Screening for hemochromatosis: high prevalence and low morbidity in an unselected population of 65,238 persons. Scand J Gastroenterol 2001;36:1108-1115.

4. Allen KJ, Gurrin LC, Constantine CC, et al. Iron-overload-related disease in HFE hereditary hemochromatosis. N Engl J Med 2008;358:221-230.

5. Petitti DP. Hereditary hemochromatosis: population screening for gene mutations. In: Khoury MJ, Bedrosian S, Gwinn M (eds). Human Genome Epidemiology. Oxford University Press: New York, 2009:639-676.

6. Adams PC. The natural history of untreated HFE-related hemochromatosis. Acta Haematol 2009;122:134-139.

7. McLaren GD, McLaren CE, Adams PC, et al. Clinical manifestations of hemochromatosis in HFE C282Y homozygotes identified by screening. Can J Gastroenterol 2008;22:923-930.

8. Ellervik C, Birgens H, Tybjaerg-Hansen A, Nordestgaard BG. Hemochromatosis genotypes and risk of 31 disease endpoints: meta-analyses including 66,000 cases and 226,000 controls. Hepatology 2007;46: 1071-1080.

9. Asberg A, Thorstensen K, Irgens WO, Romundstad PR, Hveem K. Cancer risk in HFE C282Y homozygotes: results from the HUNT 2 study. Scand J Gastroenterol 2013;48:189-195.

10. Fargion S, Fracanzani AL, Piperno A, et al. Prognostic factors for hepatocellular carcinoma in genetic hemochromatosis. Hepatology 1994;20: 1426-1431.

11. Fargion S, Mandelli C, Piperno A, et al. Survival and prognostic factors in 212 Italian patients with genetic hemochromatosis. Hepatology 1992;15: 655-659. 
12. Vanclooster A, Wollersheim H, Vanhaecht K, et al. Key-interventions derived from three evidence based guidelines for management and follow-up of patients with HFE haemochromatosis. BMC Health Serv Res 2016;16:573.

13. Leitman SF. Hemochromatosis: the new blood donor. ASH Education Book 2013;2013:645-650.

14. Adams PC, Barton JC. How I treat hemochromatosis. Blood 2010;116: 317-325.

15. Allen KJ, Bertalli NA, Osborne NJ, et al. HFE Cys282Tyr homozygotes with serum ferritin concentrations below 1000 microg/L are at low risk of hemochromatosis. Hepatology 2010;52:925-933.

16. Morabia A. Re: "The emergence of translational epidemiology: from scientific discovery to population health impact". Am J Epidemiol 2011;173:717-718; author reply, 718-719.

17. Powell LW, Dixon JL, Ramm GA, et al. Screening for hemochromatosis in asymptomatic subjects with or without a family history. Arch Intern Med 2006;166:294-301.

18. Waalen J, Felitti V, Gelbart T, Beutler E. Response: screening for treatable disease is better than just screening for hemochromatosis. Blood 2008;111:3897.

19. Beaton MD, Adams PC. Prognostic factors and survival in patients with hereditary hemochromatosis and cirrhosis. Can J Gastroenterol 2006;20: 257-260.

20. Bomford A, Williams R. Long term results of venesection therapy in idiopathic haemochromatosis. Q J Med 1976;45:611-623.

21. Milman N, Pedersen $P$, á Steig $T$, Byg $K E$, Graudal $N$, Fenger $K$. Clinically overt hereditary hemochromatosis in Denmark 1948-1985: epidemiology, factors of significance for long-term survival, and causes of death in 179 patients. Ann Hematol 2001;80:737-744.

22. Niederau $C$, Fischer $R$, Purschel A, Stremmel W, Haussinger D, Strohmeyer G. Long-term survival in patients with hereditary hemochromatosis. Gastroenterology 1996;110:1107-1119.

23. Ong SY, Dolling L, Dixon JL, et al. Should HFE p.C282Y homozygotes with moderately elevated serum ferritin be treated? A randomised controlled trial comparing iron reduction with sham treatment (Mi-iron). BMJ Open 2015;5:e008938.

24. Adams PC, Reboussin DM, Barton JC, et al. Hemochromatosis and ironoverload screening in a racially diverse population. $N$ Engl J Med 2005:352:1769-1778.

25. Phatak PD, Bonkovsky HL, Kowdley KV. Hereditary hemochromatosis: time for targeted screening. Ann Intern Med 2008;149:270-272.

26. Alexander J, Kowdley KV. HFE-associated hereditary hemochromatosis. Genet Med 2009:11:307-313.

27. Schmitt B, Golub RM, Green R. Screening primary care patients for hereditary hemochromatosis with transferrin saturation and serum ferritin level: systematic review for the American College of Physicians. Ann Intern Med 2005;143:522-536.

28. Qaseem A, Aronson M, Fitterman N, Snow V, Weiss KB, Owens DK. Screening for hereditary hemochromatosis: a clinical practice guideline from the American College of Physicians. Ann Intern Med 2005;143: 517-521.

29. Aguilar-Martinez P, Bismuth M, Blanc F, et al. The Southern French registry of genetic hemochromatosis: a tool for determining clinical prevalence of the disorder and genotype penetrance. Haematologica 2010;95:551-556.

30. U.S. Preventive Services Task Force. Screening for hemochromatosis: recommendation statement. Ann Intern Med 2006;145:204-208.

31. Crownover BK, Covey CJ. Hereditary hemochromatosis. Am Fam Physician 2013;87:183-190.

32. Manrai AK, Ioannidis JP, Kohane IS. Clinical genomics: from pathogenicity claims to quantitative risk estimates. JAMA 2016;315: 1233-1234.

33. Zaloumis SG, Allen KJ, Bertalli NA, et al. Natural history of HFE simple heterozygosity for C282Y and H63D: a prospective 12-year study. J Gastroenterol Hepatol 2015:30:719-725.

34. Beutler E, Felitti VJ, Koziol JA, Ho NJ, Gelbart T. Penetrance of 845G->A (C282Y) HFE hereditary haemochromatosis mutation in the USA. Lancet 2002:359:211-218.

35. Whitlock EP, Garlitz BA, Harris EL, Beil TL, Smith PR. Screening for hereditary hemochromatosis: a systematic review for the U.S. Preventive Services Task Force. Ann Intern Med 2006;145:209-223.

36. Rogowski WH. The cost-effectiveness of screening for hereditary hemochromatosis in Germany: a remodeling study. Med Decis Making 2009:29:224-238
37. Burt MJ, George PM, Upton JD, et al. The significance of haemochromatosis gene mutations in the general population: implications for screening. Gut 1998;43:830-836.

38. Olynyk JK, Cullen DJ, Aquilia S, Rossi E, Summerville L, Powell LW. A population-based study of the clinical expression of the hemochromatosis gene. N Engl J Med 1999;341:718-724.

39. Olynyk JK, Hagan SE, Cullen DJ, Beilby J, Whittall DE. Evolution of untreated hereditary hemochromatosis in the Busselton population: a 17-year study. Mayo Clin Proc 2004;79:309-313.

40. Andersen RV, Tybjaerg-Hansen A, Appleyard M, Birgens H, Nordestgaard $B G$. Hemochromatosis mutations in the general population: iron overload progression rate. Blood 2004;103:2914-2919.

41. Delatycki MB, Allen KJ, Nisselle $A E$, et al. Use of community genetic screening to prevent HFE-associated hereditary haemochromatosis. Lancet 2005;366:314-316.

42. Adams PC, Passmore L, Chakrabarti S, et al. Liver diseases in the hemochromatosis and iron overload screening study. Clin Gastroenterol Hepatol 2006;4:918-923.

43. Grosse SD, Kalman L, Khoury MJ. Evaluation of the validity and utility of genetic testing for rare diseases. Adv Exp Med Biol 2010;686:115-131.

44. Bonadona V, Bonaiti B, Olschwang $S$, et al. Cancer risks associated with germline mutations in MLH1, MSH2, and MSH6 genes in Lynch syndrome. JAMA 2011;305:2304-2310.

45. Bacon BR, Olynyk JK, Brunt EM, Britton RS, Wolff RK. HFE genotype in patients with hemochromatosis and other liver diseases. Ann Intern Med 1999;130:953-962.

46. Grosse SD, Morris JM, Khoury MJ. Disease-related conditions in relatives of patients with hemochromatosis. N Engl J Med 2001;344: 1477-1478.

47. Pankow JS, Boerwinkle E, Adams PC, et al. HFE C282Y homozygotes have reduced low-density lipoprotein cholesterol: the Atherosclerosis Risk in Communities (ARIC) Study. Trans/ Res 2008;152:3-10.

48. Ellervik C, Mandrup-Poulsen T, Nordestgaard BG, et al. Prevalence of hereditary haemochromatosis in late-onset type 1 diabetes mellitus: a retrospective study. Lancet 2001;358:1405-1409.

49. Asberg A, Hveem $K$, Kannelonning $K$, Irgens WO. Penetrance of the C28Y/C282Y genotype of the HFE gene. Scand J Gastroenterol 2007;42: 1073-1077.

50. Asberg A, Tretli S, Hveem K, Bjerve KS. Benefit of population-based screening for phenotypic hemochromatosis in young men. Scand $J$ Gastroentero/ 2002;37:1212-1219.

51. Phatak PD, Sham RL, Raubertas RF, et al. Prevalence of hereditary hemochromatosis in 16031 primary care patients. Ann Intern Med 1998;129: 954-961.

52. Evaluation of Genomic Applications in Practice and Prevention Working Group. Recommendations from the EGAPP Working Group: genetic testing strategies in newly diagnosed individuals with colorectal cancer aimed at reducing morbidity and mortality from Lynch syndrome in relatives. Genet Med 2009;11:35-41.

53. Grosse SD, Palomaki GE, Mvundura M, Hampel H. The cost-effectiveness of routine testing for Lynch syndrome in newly-diagnosed patients with colorectal cancer in the United States: corrected estimates. Genet Med 2015;17:510-511

54. Severin F, Stollenwerk B, Holinski-Feder E, et al. Economic evaluation of genetic screening for Lynch syndrome in Germany. Genet Med 2015;17: 765-773.

55. Snowsill T, Huxley N, Hoyle M, et al. A systematic review and economic evaluation of diagnostic strategies for Lynch syndrome. Health Technol Assess 2014:18:1-406

56. Rossi E, Olynyk JK, Jeffrey GP. Clinical penetrance of C282Y homozygous HFE hemochromatosis. Expert Rev Hematol 2008;1:205-216.

57. de Graaff B, Neil A, Si L, et al. Cost-effectiveness of different population screening strategies for hereditary haemochromatosis in Australia. Appl Health Econ Health Policy 2017;15:521-534.

58. de Graaff B, Si L, Neil AL, et al. Population screening for hereditary haemochromatosis in Australia: construction and validation of a statetransition cost-effectiveness model. Pharmacoeconom Open 2017;1:37-51.

59. Willis G, Wimperis JZ, Smith KC, Fellows IW, Jennings BA. Haemochromatosis gene $\mathrm{C} 282 \mathrm{Y}$ homozygotes in an elderly male population. Lancet 1999:354:221-222.

60. Adams PC, Pankow JS, Barton JC, et al. HFE C282Y homozygosity is associated with lower total and low-density lipoprotein cholesterol: the hemochromatosis and iron overload screening study. Circ Cardiovasc Genet 2009:2:34-37. 
61. Hulihan MM, Sayers CA, Grosse SD, Garrison C, Grant AM. Iron overload. What is the role of public health? Am J Prev Med 2011;41:422-427.

62. Fullerton $\mathrm{SM}$, Wolf WA, Brothers $\mathrm{KB}$, et al. Return of individual research results from genome-wide association studies: experience of the Electronic Medical Records and Genomics (eMERGE) Network. Genet Med 2012;14:424-431.

63. Berg JS, Amendola LM, Eng C, et al. Processes and preliminary outputs for identification of actionable genes as incidental findings in genomic sequence data in the Clinical Sequencing Exploratory Research Consortium. Genet Med 2013;15:860-867.

64. Goddard KA, Whitlock EP, Berg JS, et al. Description and pilot results from a novel method for evaluating return of incidental findings from nextgeneration sequencing technologies. Genet Med 2013;15:721-728.

65. Adams MC, Evans JP, Henderson GE, Berg JS. The promise and peril of genomic screening in the general population. Genet Med 2016;18:593-599.
66. Green RC, Berg JS, Grody WW, et al. ACMG recommendations for reporting of incidental findings in clinical exome and genome sequencing. Genet Med 2013;15:565-574.

67. Kalia SS, Adelman K, Bale SJ, et al. Recommendations for reporting of secondary findings in clinical exome and genome sequencing, 2016 update (ACMG SF V2.0): a policy statement of the American College of Medical Genetics and Genomics. Genet Med 2017;19: 249-255.

68. Burke $W$, Antommaria AH, Bennett $R$, et al. Recommendations for returning genomic incidental findings? We need to talk! Genet Med 2013;15:854-859.

69. Hunter JE, Irving SA, Biesecker LG, et al. A standardized, evidence-based protocol to assess clinical actionability of genetic disorders associated with genomic variation. Genet Med 2016;18:1258-1268. 